\title{
Undermining alienative commitment through spiritual leadership: a moderated mediation model of social capital and political skill
}

\author{
Moazzam Ali \\ Department of Management Sciences, \\ COMSATS University Islamabad - Lahore Campus, Lahore, Pakistan \\ Muhammad Usman \\ NUST Business School, National University of Sciences and Technology, \\ Islamabad, Pakistan \\ Shahzad Aziz \\ Department of Management Sciences, University of Okara, Okara, Pakistan, and \\ Yasin Rofcanin \\ School of Management, University of Bath, Bath, UK
}

Undermining alienative commitment

Received 16 September 2021 Revised 12 October 2021 Accepted 19 October 2021

\begin{abstract}
Purpose - The purpose of the present study is to examine the relationship between spiritual leadership and employees' alienative commitment to the organization, both directly and indirectly, via employee social capital. We also test the role of employee political skill as a boundary condition of the indirect spiritual leadershipalienative commitment link.

Design/methodology/approach - Time-lagged data were collected from 491 employees in various manufacturing and service organizations. Data were analyzed using structural modeling equation in Mplus (8.6). Findings - Spiritual leadership was negatively associated with alienative commitment, both directly and indirectly, via social capital. Employee political skill moderated the indirect relationship between spiritual leadership and alienative commitment, such that the relationship was stronger when employee political skill was high (vs low).

Practical implications - The demonstration of spiritual leadership's behaviors by both managers and employees can develop employees' social capital at work, which in turn can reduce employees' negative commitment to the organization. Likewise, improving employees' political skills can help leadership diminish alienative commitment.

Originality/value - The present work contributes to the literature on spiritual leadership by foregrounding how and why spiritual leadership undermines employee alienative commitment to the organization. By doing so, the study also enhances the nomological networks of the antecedents and outcomes of social capital and
\end{abstract}

\section{JEL Classification — L84, M12, M54}

(C) Moazzam Ali, Muhammad Usman, Shahzad Aziz and Yasin Rofcanin. Published in Journal of Asian Business and Economic Studies. Published by Emerald Publishing Limited. This article is published under the Creative Commons Attribution (CC BY 4.0) licence. Anyone may reproduce, distribute, translate and create derivative works of this article (for both commercial and non-commercial purposes), subject to full attribution to the original publication and authors. The full terms of this licence may be seen at http://creativecommons.org/licences/by/4.0/legalcode

Ethics Statement. The studies involving human participants were reviewed and approved by the ethics committee of the Department of Management Science, COMSATS University Islamabad, Lahore Campus. The participants provided their written informed consent to participate in this study.

Conflict of Interest Statement. The authors have no conflict of interest to disclose.

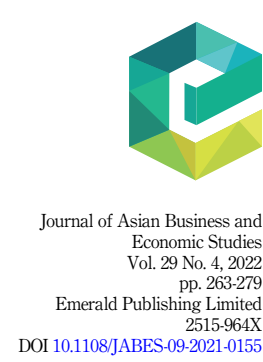


JABES 29,4 contributes to the scant literature on negative alienative commitment. Given the prevalence and negative repercussions of alienative commitment for employees' and organizations' productivity and performance, our findings are timely and relevant.

Keywords Spiritual leadership, Alienative commitment, Political skill, Social capital

Paper type Research paper

\section{4}

\section{Introduction}

Organizational commitment is considered as one of the important predictors of employees' and organizations' learning and performance and an imperative pillar in managing durable employment relationships (Hur and Perry, 2020; Parish et al., 2008). Although organizational commitment gained enormous attention in the management literature (e.g. Hur and Perry, 2020; Ruiz-Palomo et al., 2020), the analysis of the literature suggests that previous research (e.g. Hur and Perry, 2020; Ruiz-Palomo et al., 2020) has predominantly focused on positive forms of employees' attachment with the organization and surprisingly ignored alienative commitment - employees' negative affective attachment with the organization.

Alienative commitment gauges individuals' negative affective bond with the organization that can lead to several destructive repercussions for organizations, such as it can impede creativity and organizations' learning and long-term success (Hornung, 2010; Usman et al., 2021a). It undermines employees' ability to work hard and restricts them to fulfill the minimum work standards to ensure their membership with the organization. Furthermore, by limiting employees' effort to attaining minimal standards, alienative commitment hampers employees, learning, creativity and extra-role behaviors (Hornung, 2010; Penley and Gould, 1988; Usman et al., 2021a). Thus, by ignoring the negative form of commitment, previous studies (e.g. Hur and Perry, 2020; Ruiz-Palomo et al., 2020) have offered an asymmetric and restrictive view of employees' commitment to the organization and thus may impede managers' endeavors to develop appropriate interventions to influence employee commitment.

To plug this research gap, the work at hand draws on the Conservation of Resources (COR) theory (Hobfoll, 1989; Hobfoll et al., 2018) to theorize and test a model that elucidates how and why spiritual leadership reduces employees' alienative comment to the organization. Spiritual leadership refers to "comprising the values, attitudes, and behaviors that are necessary to intrinsically motivate oneself and others so that they have a sense of spiritual survival through calling and membership" (Fry, 2003, p. 711). Vision, hope/faith and altruistic love are fundamental components of spiritual leadership (Fry, 2003). We chose spiritual leadership, because "spiritual leadership's simultaneous application of social/spiritual values and rational determinants in decision making through its transcendent vision, hope/faith, and altruistic love" (Ali et al., 2020a, p. 3) differentiates it from other leadership styles (e.g. transactional leadership and transformational leadership) and fulfills followers' spiritual, as well as professional needs. Consequently, spiritual leadership inspires followers to take part in extra-role behaviors, such as employee intrapreneurial behaviors and citizenship behaviors (Bayighomog and Arasli, 2022; Chen and Li, 2013; Usman et al., 2021b) and plays an imperative role in organizations' long-term success (Fry et al., 2005). Vision and hope/faith play a crucial part to help organizations achieve goals, while altruistic love instigates employees to accomplish their spiritual quest (Bayighomog and Arasli, 2022; Fry et al., 2005, 2017). Indeed, it is a value-based leadership style that integrates vision, altruistic love and hope/faith and plays a vital role in organizational growth and development by positively shaping employees' positive attitudes and behaviors at work (Karakas, 2010). As such, based on COR theory (Hobfoll, 1989; Hobfoll et al., 2018), we understand that spiritual leadership provides employees with abundant resources such as knowledge, feedback, emotional and instrumental support, and future directions coupled with a firm faith that can 
boost their confidence to invest resources positively to strengthen their resource reservoir by acquiring new resources (e.g. job satisfaction, self-esteem and improved performance) instead of developing negative attachment with the organization that can result in loss of resources. As such, we argue that other than several positive influences on employees' work-related outcomes, spiritual leadership has substantial theoretical significance in undermining alienative commitment to the organization and its negative consequences.

Additionally, to enhance our understanding as to why spiritual leadership is negatively related to alienative commitment, the present study proposes social capital as an important mechanism underlying the spiritual leadership-alienative commitment link. The selection of social capital as a mediator is inspired by the following reasons. First, social capital helps organizations to create and develop an environment that is characterized by the norms of positive social interactions that instigate employees to exhibit positive behaviors and establish a network of meaningful relationships at work, offering them opportunities to enhance their personal resources including belongingness, knowledge and a general sense of control and competence (Anser et al., 2020a; Chang, 2017; Lau and Cobb, 2010; Usman and Ahmad, 2018). According to COR theory (Hobfoll, 1989; Hobfoll et al., 2018), resources, such as belongingness, knowledge and the general sense of control and competence activate constructive feelings and that can undermine individual work-related negative attitudes, feelings and emotions. With this line of reasoning in mind, we infer that social capital has theoretical importance and potential to reduce employees' alienative commitment to the organization. Second, past research suggests that spiritual leadership can enhance social capital by improving employees' relational wellbeing and sense of relatedness that are essential components of shaping and developing social capital (Nahapiet and Ghoshal, 1998; Subramony et al., 2018). Notably, altruistic love, an essential constituent of spiritual leadership, inspires employees to demonstrate positive behaviors, such as helping others and showing empathy that help employees build high-quality relationships (Ali et al., 2020a; Yang et al., 2019). Together, we understand that social capital can explain why spiritual leadership is negatively associated with followers' alienative commitment to the organization.

Finally, we understand that the interrelations between spiritual leadership, social capital and alienative commitment are complex rather than straightforward, as several contextual and individual-level factors can affect the strength of these interrelations. According to COR theory, individuals' differential access to various resources, such as personal traits, skills and knowledge affect the level of influence of contextual resources on their actual or expected resource gains (Hobfoll et al., 2018). To unfold the intricacies of the interrelations of spiritual leadership with social capital, and alienative commitment, we suggest political skill, an individual's personal resource, as a critical contingent factor that moderates the indirect relationship of spiritual leadership with alienative commitment via social capital. Political skill is defined as individuals' "ability to effectively understand others at work and to use such knowledge to influence others to act in ways that enhance one's personal and/or organizational objectives" (Ferris et al., 2005. p. 127). The choice of political skill as an individual contingent factor has been inspired due to the following theoretical reasons. First, political skill is an important personal resource (e.g. Hobfoll et al., 2018) that facilitates individuals to gather additional resources, such as social capital, and facilitate trust-based relationships in the workplace (Ferris et al., 2005, 2007) that we argue can diminish employees' alienative commitment to the organization. Moreover, employees high on political skill can acquire more valuable resources from their leaders (Usman et al., 2020), implying that employee political skill can play a crucial role in enhancing spiritual leaders' effectiveness in reducing employees' alienative commitment to the organization.

The present study extends the existing literature in many ways. First, by empirically testing the role of spiritual leadership in reducing employees' alienative commitment to the organization, the work at hand adds to the scarce pool of studies on alienative commitment
Undermining alienative commitment 
JABES 29,4

\section{6}

(Hornung, 2010; Usman et al., 2021a). The finding has opened a new scholarly debate that would draw their attention to revisit a form of organizational commitment that has largely been glossed over in the conventional commitment literature. Second, the present study extends the literature on the spiritual leadership-commitment relationship (Djaelani et al., 2021; Fry et al., 2005) by offering a more nuanced understanding of this relationship by focusing on the negative aspects of employee commitment to the organization and thus enhance the nomological network of the outcomes of spiritual leadership.

Third, by empirically examining social capital as an underlying mechanism in the direct association of spiritual leadership with alienative commitment, the study extends the literature on social capital (Chang, 2017; Nahapiet and Ghoshal, 1998; Subramony et al., 2018). Finally, the present study foregrounds employee political skill as an important factor that can enhance the effectiveness of spiritual leadership in undermining employees' alienative commitment to the organization. Although previous research brings to the fore several positive outcomes of employee political skill (Crawford et al., 2019; Kim et al., 2019; Usman et al., 2020), none of the studies has examined the role of employee political skill in the spiritual leadership-alienative commitment link. Our findings that political skill strengthens the negative relationship between spiritual leadership and employee alienative commitment is imperative. The hypothesized model is shown in Figure 1.

\section{Theory and hypotheses development}

Spiritual leadership and alienative commitment

Alienative commitment is triggered due to a lack of control over work activities, environmental pressure and the lack of alternatives (Hornung, 2010; Penely and Gould, 1988; Usman et al., 2021a). Alienatively committed individuals often do not have the option of quitting the organization because of the financial obligation that he/she has to fulfill to meet his/her family needs (Usman et al., 2021a). Moreover, alienatively committed workers strive to fulfill the threshold criteria sufficient to help them stay with the organization (Hornung, 2010; Penely and Gould, 1988). Alienative commitment can have destructive influences on employees and organizations because of its low intensity and ambiguous nature and is often a challenge for managers to identify (Etzioni, 1961; Penley and Gould, 1988).

Past research has highlighted that alienative commitment creates employees' random perception about the punishment and rewards and undermines their performance-based view of punishment and rewards (Hornung, 2010; Penley and Gould, 1988). This random perception gives rise to a number of negative outcomes including anxiety, frustration and

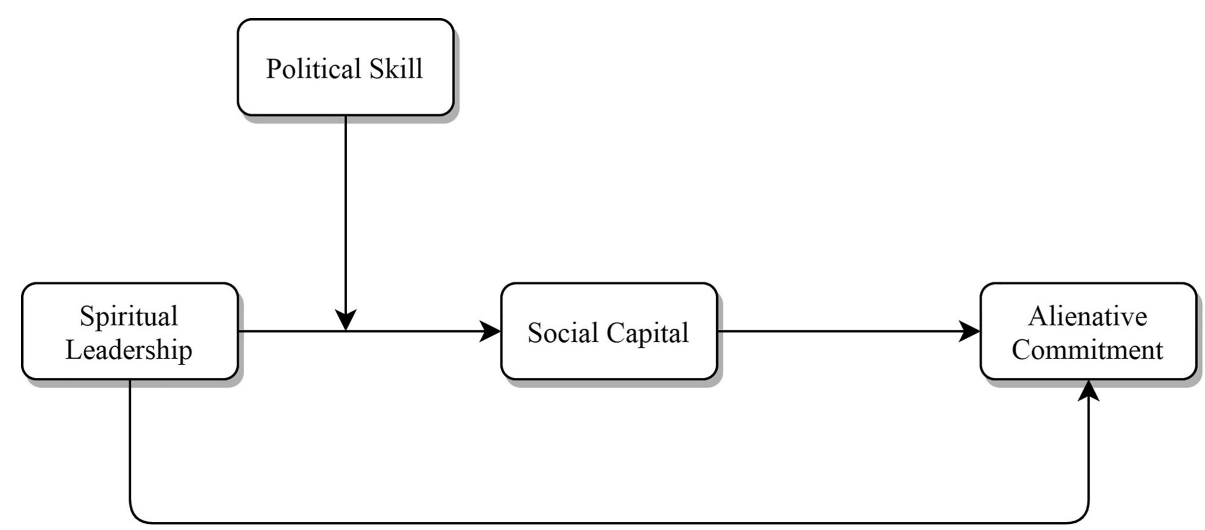

Figure 1.

The proposed model 
purposelessness. Moreover, it undermines employees' ability to work hard and restricts their endeavors toward fulfilling the minimal work standards to ensure their membership with the organization. Furthermore, by limiting employees' effort to minimal standards, alienative commitment hampers employees' learning, creativity and extra-role efforts (Hornung, 2010; Penley and Gould, 1988; Usman et al., 2021b). Alienative commitment is a prevailing workplace phenomenon, and as noted by (Usman et al., 2021), "past research has offered an asymmetric view of the concept of employees' commitment to the organization by focusing mainly on the positive aspects and glossing over the negative aspect of commitmentalienative commitment" (p. 283). Glossing over this negative form of commitment can risk leaving its consequences and predictors unattended.

Building on COR theory, the present study contends that spiritual leadership can undermine employees' alienative commitment - employees' negative affective attachment with the organization. This contention is grounded upon the following theoretical reasons. For example, spiritual leaders, through a transcendent vision together with altruistic love and hope/faith, intrinsically motivate employees to gain a sense of calling and membership (Fry et al., 2005). Intrinsic motivation empowers employees to perform work activities to fulfill their task requirements in a way that can enhance their spiritual wellbeing (Wang et al., 2019). Empowered employees can shape and develop their autonomous internalization to perform their work roles (Nguyen et al., 2020; Teng, 2019), suggesting that spiritual leadership, through altruistic love and hope/faith, inspires employees to go beyond minimum role requirements to perform extra-role behaviors.

Additionally, spiritual leadership, through altruistic love, develop a work environment that is characterized by a focus on helping and caring for others and the exchange of resources from leaders to employees that give employees a sense of control over their jobrelated activities (Bayighomog and Arasl1, 2019; Usman et al., 2021b). Importantly, spiritual leaders, through collective social influence processes, align individuals' and the organization's values that inculcate employees' feelings of belongingness to the organization and its members (Fry et al., 2005). Moreover, spiritual leadership, through consistent guidance and a bottom-up interactional approach, enhances followers' sense of autonomy that encourages them to extend efforts beyond minimum job requirements (Anser et al., 2021; Bayighomog and Arasli, 2022). Thus, seen through the lens of COR theory, spiritual leadership as a contextual resource enhances employees' personal resources, such as their sense of autonomy, spiritual wellbeing, intrinsic motivation and autonomous motivation that they may invest in behaviors to enhance their personal resources instead of limiting their resource investment to minimum job requirements by developing a negative affective attachment with the organization that may hinder their future resource gains. Thus, it is likely that spiritual leaders can undermine employees' negative affective attachment to the organization. Thus, the present study builds the subsequent hypothesis.

H1. Spiritual leadership is negatively associated with employees' alienative commitment to the organization.

\section{Social capital as a mediator}

COR theory posits that resources are interconnected, and thus increase in spirals. Furthermore, the theory suggests that positive contextual resources help individuals boost up their personal resources (Hobfoll et al., 2018), such as trust-based relationships with peers, knowledge, meaningfulness and a sense of control over the work and the work context. Building on COR theory, we understand that it is likely that spiritual leadership as a contextual resource will help followers build strong networks of relationships and enhance employees' personal resources, such as a general sense of control and meaningfulness are increased. Consequently, employees' feelings of a lack of control and work pressure can be reduced.
Undermining alienative commitment

\section{(n)}


JABES 29,4

\section{8}

Previous studies suggest that by the virtue of intellectual discourse and bottom-up interactional approach, spiritual leadership encourages followers to develop and maintain trust-based connections with peers (Fry et al., 2005; Usman et al., 2021b). These quality relationships inspire followers to share their knowledge and skills with coworkers to assist them to overcome work-related issues and enhance their interpersonal trust and confidence (Usman et al., 2021b). Spiritual leadership instigates their followers' quest for acquiring the transcendental meanings of their work activities that broaden their work perspective and instill a sense of serving others and the community (Fry et al., 2017). By attaching transcendental meaning to the work and enhancing knowledge sharing, spiritual leadership provides followers opportunities to enhance their social capital at work.

Proceeding further, spiritual leadership, through altruistic love, fosters a climate based on mutual respect and care that leads to positive behaviors, such as forgiveness, gratitude and appreciating others for their contributions (Bayighomog and Arasli, 2022). These positive behaviors provide a basis for the high-quality relationship among followers in the workplace and help eliminate the structural rigidities that hinder meaningful sharing of values, knowledge and information (Ali et al., 2020a; Bayighomog and Arasl1, 2019; Fry et al., 2017) and as such can enhance employees' social capital. Prior research on social capital has revealed that social capital facilitates and promotes a collaborative work environment that encourages smooth communication and meaningful social interactions, leading to employees' high-quality interpersonal relationships at work (Chang, 2017; Nahapiet and Ghoshal, 1998).

The high-quality interpersonal relationship not only lessens work pressure but also enhances employees' sense of cooperation at work that reduces the need for monitoring (Muniady et al., 2015). Furthermore, meaningful exchanges broaden employees' sense of accomplishment and meaningfulness (Chang, 2017; Kroll et al., 2019; Muniady et al., 2015). The enhanced sense of meaning at work shapes employees' general perception of control (Frankl, 1961). Social capital, by enhancing individuals' sense of control and reducing work pressure, is likely to reduce alienative commitment, as the lack of control and work pressure are fundamental constituents of employees' alienative commitment. Based on these arguments we postulate the following hypothesis.

H2. Social capital mediates the negative relationship between spiritual leadership and employees' alienative commitment to the organization.

\section{Political skill as a moderator}

COR theory proposes that employees with more resources have a better ability to generate more resources. That is, employees with more personal resources than their counterparts have a better propensity to benefit more from contextual resources, such as spiritual leadership. In other words, the strength of association between spiritual leadership and employees' outcomes at work may vary across individuals, and thus the effect of spiritual leadership on employee outcomes can be heterogeneous (Yang et al., 2019; Usman et al., 2021). To gauge this heterogeneity, the work at hand proposes that the indirect relationship between spiritual leadership and alienative commitment via social capital is contingent on employee political skill.

Based on COR theory, we argue that individuals with better political skills have better ability to develop social relations and understand the relational dynamics of these networks and thus can utilize these relationships to strengthen their resource reservoirs more effectively (Fang et al., 2015; Nahapiet and Ghoshal, 1998). Moreover, political skills equip individuals to manage better access to contextual resources, such as spiritual leadership and positively exploit available contextual resources to enhance their social capital (Fang et al., 2015). This indicates that as compared with others, the effect of spiritual leadership on social capital is likely to be strong for employees high on political skills. 
Indeed, individuals with high political skill have a strong ability to understand and better mobilize the resources embedded in these networks (Ferris et al., 2005; Usman et al., 2020). Political skill enables individuals to build networks of relationships through their networking ability that helps individuals to gain valuable resources and enhances the social interaction environment at the workplace (Ferries et al., 2005, 2007). Politically skilled individuals can better identify with others and handle the rigid structures of social networks to facilitate the smooth flow of information that helps them to build trust-based, high-quality relationships with others at work (Ferries et al., 2005, 2007). As such, it is likely that as compared with their counterparts, individuals high on political skill are better able to influence and take advantage of the resources provided by spiritual leadership in developing their social capital. As such, it can be inferred that the influence of spiritual leadership on social capital is more pronounced for employees with high political skill than those with low political skill. Further, as noted earlier (H2), spiritual leadership enhances employees' social capital, which in turn negatively influences alienative commitment. Put it differently, the influence of spiritual leadership on alienative commitment is translated through social capital. Thus, together, it can be inferred that the indirect effect of spiritual leadership on alienative commitment via social capital is contingent on the level of employee political skill. Seen through the statistical perspective, this is the case of moderated mediation (Hayes, 2015), whereby employee political skill interacts with spiritual leadership to indirectly affect commitment alienative via social capital, such that the relationship is strong when political skill is high. Therefore, we developed the following hypothesis.

H3. Employee political skill moderates the indirect (via social capital) relationship between spiritual leadership and alienative commitment, such that the relationship is stronger when political skill is high (vs low).

\section{Method \\ Sampling and data collection}

The present study collected data from employees who were enrolled as students in the Master's in Business Administration (MBA) program in different public sector universities in Pakistan. These students were working as fulltime at various levels in different service and manufacturing organizations belonging to telecommunication, textile manufacturing, ceramics, energy, banking, hospitality and tourism, and information technology. The objective of gathering data from diverse service and manufacturing sectors was to capture maximum variance in spiritual leadership and its impacts on social capital and alienative commitment to enriching the generalizability of the study (Abbas et al., 2014). As the purpose of the study was to empirically test the hypothesized relationship between spiritual leadership, social capital, alienative commitment and political skill, we used a quantitative survey data collection approach. The present study employed a time-lagged strategy (Ali et al., 2021; Anser et al., 2020b; Usman et al., 2021a), where each round of data collection was separated by three weeks. The purpose of collecting time-lagged data was to avoid common method bias (Podsakoff et al., 2003).

Initially, $600 \mathrm{MBA}$ students were approached and emailed an information sheet explaining the purpose and objectives of the study along with the promise of anonymity and an opportunity to attend an online training workshop on Mplus. We obtained written consent from 567 students who were willing to participate in all three rounds of data collection. In the first round, the respondents were sent an email containing a link to the survey regarding the independent variable (spiritual leadership), the moderator (political skill) and control variables (demographic controls, such as age, gender, education and experience). In the second round, the survey about the mediator (social capital) was emailed to
Undermining alienative commitment 
JABES 29,4

\section{0}

those respondents who have successfully submitted the survey in the first round. Similarly, in the third round, the survey about the outcome variable (alienative commitment) was emailed to those respondents who have successfully submitted the survey in the second round.

We received filled surveys from 544,523 and 509 respondents in the first, second and third rounds, respectively. After careful screening and matching the unique codes for all three rounds, 491 ( $80.85 \%$ net response rate) useable responses were retained and utilized to assess the hypothesized relationships. The final sample had $56.6 \%$ males and $43.4 \%$ females. The average age and average tenure were 36.23 and $33.07 \%$ respectively. In terms of industry, $57.6 \%$ of the respondents belonged to the service industry while $43.4 \%$ belonged to the manufacturing industry. To analyze the numeric data collected through the survey, we employed structural equation modeling (SEM) in Mplus (8.6). We used Hair et al. (2010) minimum sample size formula for SEM. Minimum sample $=($ Number of indicators + number of latent variables) $\times$ (estimated parameters) Minimum sample $=(56+4) \times 6=360$ respondents. Our sample was 491 responses which is well above the minimum.

\section{Measures and variables}

The present study measured all the understudied constructs using Likert-type scales anchored on 1 (strongly disagree) to 5 (strongly agree).

Spiritual leadership. Spiritual leadership was measured by adapting a 17 -item scale (Cronbach alpha $=0.77)$ by Fry et al. (2005). Sample item: "I have faith in my leadership's vision for its employees".

Social capital. Social capital was assessed by adapting a 16-item scale (Cronbach alpha $=0.76$ ) by Chang (2017). Sample item: "I usually exchange ideas and information with people in my organization".

Alienative commitment. Alienative Commitment was measured using a 5-item scale $($ Cronbach alpha $=0.85)$ by Penley and Gould (1988). Sample items: "I get angry when I think about this organization", and "I feel trapped here".

Political skill. Political skill was measured using 18-item political skill inventory (Cronbach alpha $=0.81$ ) by Ferris et al. (2005). Sample item: "At work, I know a lot of important people and am well connected”.

Control variables. Demographic variables such as age, gender, experience and industry type can have potential influences on the social capital (Poortinga, 2006; Veenstra, 2000) and alienative commitment (Usman et al., 2021a) and thus can confound the results. Against this backdrop, the present study controlled for these demographic variables to enhance the understanding of the hypothesized relationships.

\section{Results}

Mean and correlation

Means, standard deviations and correlations are presented in Table 1.

\section{Measurement model}

We performed a series of confirmatory factor analyses (CFAs) using Mplus 8.6 to investigate the model fitness and establish convergent and discriminant validities. The results (Table 2) revealed that our proposed four factors model including spiritual leadership, social capital, alienative commitment and political skill demonstrated a suitable fit- $\chi^{2}(84)=171.44$, $\chi^{2} / \mathrm{df}=2.04, \mathrm{RMSEA}=0.05, \mathrm{SRMR}=0.04, \mathrm{CFI}=0.96, \mathrm{TLI}=0.95-$ as compared to the two-factor and single-factor alternative models. 


\begin{tabular}{|c|c|c|c|c|c|c|c|c|c|c|}
\hline Construct & Means & $\mathrm{Sd}$ & 1 & 2 & 3 & 4 & 5 & 6 & 7 & dermining \\
\hline 1. Spiritual leadership & 2.92 & 0.89 & - & & & & & & & commitment \\
\hline 2. Social capital & 2.93 & 0.97 & $0.26^{* *}$ & - & & & & & & \\
\hline $\begin{array}{l}\text { 3. Alienative } \\
\text { commitment }\end{array}$ & 2.76 & 1.14 & $-0.16^{* *}$ & $-0.26^{* *}$ & - & & & & & \\
\hline 4. Political skill & 3.29 & 0.67 & -0.04 & -0.05 & 0.01 & - & & & & \\
\hline 5. Age & 36.23 & 7.74 & 0.00 & -0.01 & 0.01 & 0.04 & - & & & 27 \\
\hline 6. Gender & 1.43 & 0.49 & 0.03 & 0.06 & -0.05 & 0.01 & -0.06 & - & & \\
\hline 7. Tenure & 3.07 & 1.38 & 0.03 & -0.01 & -0.05 & -0.02 & -0.02 & -0.03 & - & \\
\hline 8. Industry type & 1.58 & 0.49 & 0.02 & 0.05 & -0.07 & -0.02 & -0.03 & -0.02 & -0.07 & \\
\hline
\end{tabular}

Note(s): $N=491 . * p<0.05 . * * p<0.01$ level (2-tailed). $\mathrm{SD}=$ standard deviation. Gender: $1=$ male, $2=$ female. Industry Type 1 = Manufacturing, 2 = Service

Table 1. Means and correlations

\begin{tabular}{|c|c|c|c|c|c|c|c|c|c|}
\hline Models & Factors & $\chi^{2}$ & $\mathrm{df}$ & $\chi^{2} / \mathrm{df}$ & $\Delta \chi^{2}$ & RMSEA & SRMR & CFI & \\
\hline & & & 8 & 2.04 & & & 0 & & \\
\hline & & & 89 & 12 & & & & & \\
\hline Model 3 & 1 factor: $\mathrm{SL}+\mathrm{SC}+\mathrm{AC}+\mathrm{PS}$ & 1459.80 & 90 & 16.22 & 369.30 & 0.18 & 0.15 & 0.43 & \\
\hline
\end{tabular}

Note(s): $\mathrm{SL}=$ Spiritual leadership, $\mathrm{SC}=$ Social capital, $\mathrm{AC}=$ Alienative Commitment, $\mathrm{PS}=$ Political skill

Table 2 .

Confirmatory factor analysis of discriminate validity

\section{Hypotheses testing}

To assess the hypothesized relationships, we employed SEM in MPlus (8.6). The results (Table 3) confirmed a significant negative association between spiritual leadership and alienative commitment $(B=-0.30, S E=0.08, p<0.01)$. Thus, hypothesis 1 was supported. Proceeding further, the results also confirmed a significant negative indirect relationship between spiritual leadership and employees' alienative commitment $(B=-0.12, S E=0.04$, $p<0.01)$ via social capital. Thus, hypothesis 2 was supported.

The moderation analysis showed that the index of moderated mediation was significant for the theorized indirect relationship between spiritual leadership and employees' alienative commitment (index $=-0.08, S E=0.03, C I=[-0.13,-0.02]$ ), via employees' social capital. The conditional indirect effect to alienative commitment $(B=-0.18, S E=0.03, p<0.01)$ via employees' social capital was significant for employees high on political skill; while it was insignificant for the employees low on political skill $(B=0.02, n s)$. We followed Edwards and Lambert's (2007) Mediated Interaction Effect Drawing Method to plot this conditional indirect effect as shown in Figure 2. Thus, hypothesis 3 was supported.

\begin{tabular}{lrc}
\hline Direct paths & $B$ & SE \\
\hline Spiritual leadership $\rightarrow$ alienative commitment & $-0.30^{* * *}$ & 0.08 \\
Spiritual leadership $\rightarrow$ social capital & $0.37^{* * *}$ & 0.07 \\
Social capital $\rightarrow$ alienative commitment & $-0.33^{* *}$ & 0.08 \\
Indirect paths & & \\
Spiritual leadership $\rightarrow$ social capital $\rightarrow$ alienative commitment & $-0.12^{* *}$ & 0.04 \\
Moderated Paths & & \\
Spiritual leadership * political skill $\rightarrow$ social capital & $0.27^{* *}$ & 0.06 \\
Spiritual leadership * political skill $\rightarrow$ social capital $\rightarrow$ alienative commitment & $-0.08^{* *}$ & 0.03
\end{tabular}

Note(s): $N=491, B=$ Unstandardized coefficient, $\mathrm{SE}=$ Standard error, Bootstrapping specified at 5000 with $95 \%$ confidence interval

Table 3.

Hypothesis testing results 
JABES

Conditional Indirect Effect for Employee Political Skill
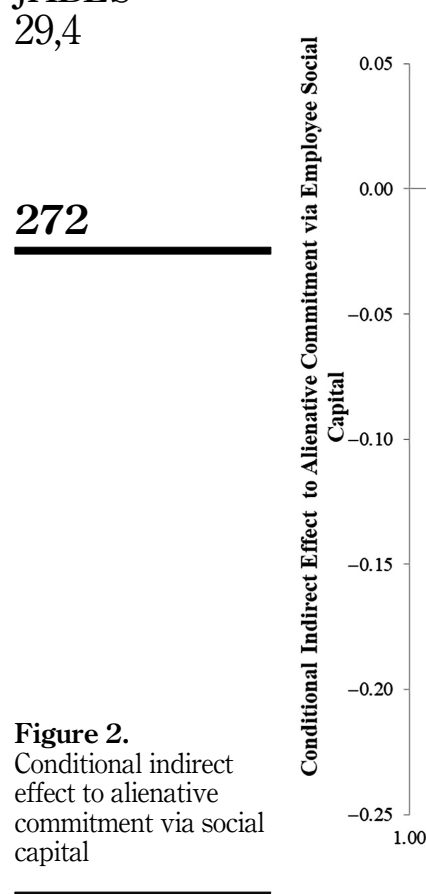

10
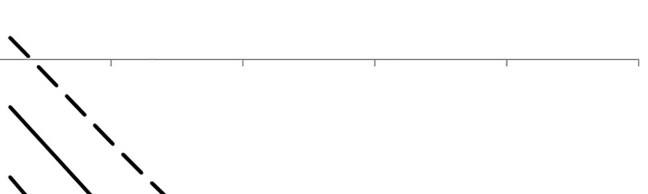
, $\searrow_{1}$ 1 $1>$ $11_{1}^{1}$ .00

2.00

2.50

3.00

3.50

4.00

4.50

5.00

Level of Moderator: Employee Political Skill

\section{Discussion}

Despite several harmful effects of alienative commitment for employees and organizations, our knowledge as to how managers can resolve the issue of employee alienative commitment is scarce. To resolve this issue, the present study developed a model that predicted a negative relationship between spiritual leadership and employee alienative commitment. Specifically, the present work hypothesized that spiritual leadership is negatively related to employee alienative commitment, both directly and indirectly, via employee social capital. The study also proposed that employee political skill moderates the indirect (via social capital) relationship between spiritual leadership and alienative commitment such that the relationship is strong when employee political skill is high. Time-lagged survey data collected from 491 employees working in various manufacturing and service organizations operating in Pakistan and analyzed using SEM in Mplus (8.6) supported our hypotheses.

\section{Theoretical contributions}

The present study extends the existing literature in many ways. First, by empirically revealing a significant negative relationship between spiritual leadership and employee alienative commitment, the work at hand enriches the limited yet growing literature on spiritual leadership (Fry et al., 2005; Wang et al., 2019; Usman et al., 2021b). Based on COR theory, our findings signify that spiritual leadership, through vision, altruistic love and hope/ faith, enhances employees' several personal resources, such as their sense of autonomy, spiritual wellbeing, intrinsic motivation and autonomous motivation that negatively influence employees' negative attachment with the organization. In so doing, the work at hand also responds to the recent research calls (Ali et al., 2020a; Usman et al., 2021b) to add 
research studies on the limited yet growing pools of research on the outcomes of spiritual leadership.

Second, by empirically revealing a significant negative relationship between spiritual leadership and alienative commitment, the present study extends the literature on organizational commitment that has mainly focused on the positive aspects of commitment, such as affective and instrumental forms of commitment (Djaelani et al., 2021; Fry et al., 2005). The present work markedly deviates from and contributes to the existing literature on organizational commitment (Ruiz-Palomo et al., 2020) by focusing on the negative affective commitment that has serious negative consequences for the employees and organizations. Given the lack of research on negative aspects of organizational commitment and its harmful consequences (Usman et al., 2021a), this finding is relevant.

Third, although previous studies have revealed the direct links between social capital and several employees' work-related outcomes, such as job performance, affective commitment and learning (Chang, 2017; Kroll et al., 2019), the important role that social capital plays in the spiritual leadership-alienative commitment link have been overlooked. By establishing social capital as an underlying mechanism of the relationship between spiritual leadership and alienative commitment, the present study advances our understanding as to why spiritual leadership is negatively related to alienative commitment. By doing so, the present study contributes to the existing literature on spiritual leadership (Ali et al., 2020a, b; Fry et al., 2017; Wang et al., 2019) and also extends the empirical research on social capital (Abdullah et al., 2019; Chang, 2017; Kroll et al., 2019).

Finally, the results demonstrated the indirect relationship between spiritual leadership and alienative commitment was significant for employees high on political skill as compared to employees low on political skill. Our findings indicate that employees high on political demonstrate a better ability to learn from spiritual leadership that sharpens their capabilities to build and maintain high-quality relationships with others and reduce their alienative commitment with the organization. Thus, the present study foregrounds an important yet overlooked role of employee political skill in the spiritual leadership-alienative commitment and explains when spiritual leadership is more effective in undermining alienative commitment and thus contributes to the existing literature on employee political skill (Ferris et al., 2007; Usman et al., 2020).

\section{Practical implications}

The work at hand provides practical guidelines that can guide managers to diminish and eradicate the employees' negative attitudes workplace such as alienative commitment. First, the findings indicate the vital role of spiritual leadership in reducing employees' alienative commitment to the organization. Managers should emphasize instilling in employees a sense of control and transcendental values of work activities from top to bottom. To accomplish this end, organizations should formulate a clear vision that integrates spiritual values as a key component for the development of employees, organizations and the community. To instill key spiritual values, the organizations should develop training programs and workshops that are aiming at building and developing a workplace that is characterized by spiritual values such as fostering positive energy and spirit and equipping them with faith in the leadership's vision and hope for striving for the good future. The organizations incorporate spiritual values in different management practices that can help managers understand their role as spiritual leaders. Managers as spiritual leaders can also transmit these spiritual behaviors to their employees through motivational sessions and by demonstrating these values through behaviors and decisions. By doing so, managers would enhance employees' sense of meaningfulness that can inspire them to think about their work activities beyond a mere financial transaction and reduce their negative attachment with the organization.
Undermining alienative commitment 
JABES 29,4
Second, past research has highlighted that alienative commitment is covert in nature as employees often do not share their feelings with co-workers and managers (Hornung, 2010; Penley and Gould, 1988; Usman et al., 2021b). Therefore, it is tricky for managers to identify and handle these types of attitudes. To address this, managers as spiritual leaders can encourage employees' participation in decision-making that would enhance employees' general sense of control over the work activities and lessen the unnecessary pressure that they feel in the workplace. This would reduce their feelings of alienative commitment. Third, managers as spiritual leaders can use emotion regulation strategies to shape employees' attitudes and behaviors positively. Fourth, organizations should equip the hiring process with spirituality screening tests to identify and select the employees having an orientation towards spirituality. To achieve, this end, managers can utilize the intrinsic spirituality scale that would allow them to access the applicant's orientation toward spirituality.

Fifth, the work at hand indicates the important role that social capital can play in diminishing employees' alienative commitment to the organization. Managers as spiritual leaders can encourage a work environment that is characterized by care and concern for others, helping others to accomplish their spiritual needs and ideas and knowledge sharing that would create a sense of inclusion and reduce their negative identification with the organization. To achieve this end, managers should devise tasks that are interdependent and appreciate and acknowledge employees' efforts in helping and facilitating their peers. By doing so, managers can nurture employees' social capital that in turn can reduce their negative attitudes toward work and organization.

Finally, we suggest that organizations incorporate political skill as a key ingredient in training programs that would help shape and develop employees' capabilities to develop networks and use resources from these networks in the execution of their work roles more effectively. Managers can organize mentoring and coaching sessions not only to highlight the importance of their political skills and help them sharpen their networking abilities. The organization should also deploy the political skill inventory (Ferris et al., 2005) as a screening test for hiring new employees that would indicate their political skill which can be nurtured further with the help of mentoring, coaching and different skill-building programs.

\section{Limitation and future research directions}

Despite having certain strengths, the present study also has few notable limitations. Although the present study collected time-lagged survey data to avoid common method variance, the self-reported data precludes causal inferences. Thus, we invite researchers to build a longitudinal research design to gain a deeper insight into the causal inferences of the proposed model. Moreover, Kelemen et al. (2020) have highlighted that leadership practices and behaviors have a certain amount of variation in their day-to-day practice and experience and that sampling or daily dairy study design can provide a deep understanding of leading leaders' day-to-day behaviors and their effects on employees' work-related attitudes at work. We urge scholars to employ an experience sampling or daily dairy study design to gauge the moment-to-moment variance rather than using a static approach. This would enhance the finding and enrich the literature.

Additionally, the present study has empirically demonstrated that spiritual leadership has a negative relationship with alienative commitment. Past research (e.g. Anser et al., 2021) has highlighted that ethical leadership preach and practice care and concerns for each other's and encourage strong two-way communication to enhance employees' role in participatory decision making that is likely to enhance their sense of control over work activities and sense of purpose. Against this backdrop, the present study opens a new avenue for future scholars to explore the influence of ethical leadership on alienative commitment. 


\section{References}

Abbas, M., Raja, U., Darr, W. and Bouckenooghe, D. (2014), "Combined effects of perceived politics and psychological capital on job satisfaction, turnover intentions, and performance", Journal of Management, Vol. 40 No. 7, pp. 1813-1830.

Abdullah, M.I., Dechun, H., Ali, M. and Usman, M. (2019), "Ethical leadership and knowledge hiding: a moderated mediation model of relational social capital, and instrumental thinking", Frontiers in Psychology, Vol. 10 No. 2403, pp. 1-11.

Ali, M., Usman, M., Pham, N.T., Agyemang-Mintah, P. and Akhtar, N. (2020a), "Being ignored at work: understanding how and when spiritual leadership curbs workplace ostracism in the hospitality industry", International Journal of Hospitality Management, Vol. 91 No. 102696, doi: 10.1016/j. ijhm.2020.102696.

Ali, M., Aziz, S., Pham, T.N., Babalola, M.T. and Usman, M. (2020b), "A positive human health perspective on how spiritual leadership weaves its influence on employee safety performance: the role of harmonious safety passion”, Safety Science, Vol. 131, p. 104923, doi: 10.1016/j.ssci.2020.104923.

Ali, M., Qu, Y.E., Shafique, S., Pham, N.T. and Usman, M. (2021), "The role of ethical leadership in enhancing exploitative and explorative learning simultaneously: what does it matter if employees view work as central?", Personnel Review. doi: 10.1108/PR-12-2019-0708.

Anser, M.K., Ali, M., Anwar, F. and Usman, M. (2020), "Subjective age and job satisfaction: a moderated mediation model of job burnout and chronological age", Frontiers in Public Health, Vol. 8 No. 62, pp. 1-11.

Anser, M.K., Yousaf, Z., Usman, M., Yousaf, S., Fatima, N., Hussain, H. and Waheed, J. (2020a), "Strategic business performance through network capability and structural flexibility", Management Decision, Vol. 59 No. 2, pp. 426-445.

Anser, M.K., Ali, M., Usman, M., Rana, M.L.T. and Yousaf, Z. (2021), "Ethical leadership and knowledge hiding: an intervening and interactional analysis", The Service Industries Journal, Vol. 41 Nos 5-6, pp. 307-329.

Bayighomog, S.W. and Arasl, H. (2019), "Workplace spirituality-customer engagement Nexus: the mediated role of spiritual leadership on customer-oriented boundary-spanning behaviors", The Service Industries Journal, Vol. 39 Nos 7-8, pp. 637-661.

Bayighomog, S.W. and Arasli, H. (2022), "Reviving employees' essence of hospitality through spiritual wellbeing, spiritual leadership, and emotional intelligence”, Tourism Management, Vol. 89, 104406, doi: 10.1016/j.tourman.2021.104406.

Chang, M.L. (2017), "On the relationship between intragroup conflict and social capital in teams: a longitudinal investigation in Taiwan”, Journal of Organizational Behavior, Vol. 38 No. 1, pp. 3-27.

Chen, C.Y. and Li, C.I. (2013), "Assessing the spiritual leadership effectiveness: the contribution of follower's self-concept and preliminary tests for moderation of culture and managerial position", The Leadership Quarterly, Vol. 24 No. 1, pp. 240-255.

Crawford, W.S., Lamarre, E., Kacmar, K.M. and Harris, K.J. (2019), "Organizational politics and deviance: exploring the role of political skill”, Human Performance, Vol. 32 No. 2, pp. 92-106.

Djaelani, A., Sanusi, A. and Trianmanto, B. (2021), "Spiritual leadership, job Satisfaction, and its effect on organizational commitment and organizational citizenship behavior", Management Science Letters, Vol. 10 No. 16, pp. 3907-3914.

Etzioni, A. (1961), A Comparative Analysis of Complex Organizations, Free Press, New York, NY.

Fang, R., Landis, B., Zhang, Z., Anderson, M.H., Shaw, J.D. and Kilduff, M. (2015), "Integrating personality and social networks: a meta-analysis of personality, network position, and work outcomes in organizations", Organization Science, Vol. 26 No. 4, pp. 1243-1260.

Ferris, G.R., Treadway, D.C., Kolodinsky, R.W., Hochwarter, W.A., Kacmar, C.J., Douglas, C. and Frink, D.D. (2005), "Development and validation of the political skill inventory", Journal of Management, Vol. 31 No. 1, pp. 126-152.

Undermining alienative commitment 
JABES 29,4

Ferris, G.R., Treadway, D.C., Perrewé, P.L., Brouer, R.L., Douglas, C. and Lux, S. (2007), "Political skill in organizations", Journal of Management, Vol. 33 No. 3, pp. 290-320.

Frankl, V.E. (1961), "Dynamics, existence and values", Journal of Existential Psychiatry, Vol. 2 No. 5, pp. 5-16.

Fry, L.W. (2003), “Toward a theory of spiritual leadership”, The Leadership Quarterly, Vol. 14 No. 6, pp. 693-727.

Fry, L.W., Vitucci, S. and Cedillo, M. (2005), "Spiritual leadership and army transformation: theory, measurement, and establishing a baseline", The Leadership Quarterly, Vol. 16 No. 5, pp. 835-862.

Fry, L.W., Latham, J.R., Clinebell, S.K. and Krahnke, K. (2017), "Spiritual leadership as a model for performance excellence: a study of Baldrige award recipients", Journal of Management, Spirituality and Religion, Vol. 14 No. 1, pp. 22-47.

Hair, J., Black, W.C., Babin, B.J. and Anderson, R.E. (2010), Multivariate Analysis, 7th ed., Pearson Education International, Upper saddle River, NJ.

Hayes, A.F. (2015), "An index and test of linear moderated mediation", Multivariate Behavioral Research, Vol. 50 No. 1, pp. 1-22.

Hobfoll, S.E. (1989), "Conservation of resources: a new attempt at conceptualizing stress", American Psychologist, Vol. 44 No. 3, pp. 513-524.

Hobfoll, S.E., Halbesleben, J., Neveu, J.P. and Westman, M. (2018), "Conservation of resources in the organizational context: the reality of resources and their consequences", Annual Review of Organizational Psychology and Organizational Behavior, Vol. 5, pp. 103-128.

Hornung, S. (2010), "Alienation matters: validity and utility of Etzioni's theory of commitment in explaining prosocial organizational behavior", Social Behavior and Personality: An International Journal, Vol. 38 No. 8, pp. 1081-1095.

Hur, H. and Perry, J.L. (2020), "Job security rule changes and employee organizational commitment", Review of Public Personnel Administration, Vol. 40 No. 4, pp. 641-668.

Karakas, F. (2010), "Spirituality and performance in organizations: a literature review", Journal of Business Ethics, Vol. 94 No. 1, pp. 89-106.

Kelemen, T.K., Matthews, S.H. and Breevaart, K. (2020), "Leading day-to-day: a review of the daily causes and consequences of leadership behaviors", The Leadership Quarterly, Vol. 31 No. 1, p. 101344.

Kim, T.T., Karatepe, O.M. and Chung, U.Y. (2019), "Got political skill? The direct and moderating impact of political skill on stress, tension and outcomes in restaurants", International Journal of Contemporary Hospitality Management, Vol. 31 No. 3, pp. 1367-1389.

Kroll, A., DeHart-Davis, L. and Vogel, D. (2019), "Mechanisms of social capital in organizations: how team cognition influences employee commitment and engagement", The American Review of Public Administration, Vol. 49 No. 7, pp. 777-791.

Lau, R.S. and Cobb, A.T. (2010), "Understanding the connections between relationship conflict and performance: the intervening roles of trust and exchange", Journal of Organizational Behavior, Vol. 31 No. 6, pp. 898-917.

Muniady, R.A.L., Mamun, A.A., Mohamad, M.R., Permarupan, P.Y. and Zainol, N.R.B. (2015), "The effect of cognitive and relational social capital on structural social capital and micro-enterprise performance”, Sage Open, Vol. 5 No. 4, 2158244015611187.

Nahapiet, J. and Ghoshal, S. (1998), "Social capital, intellectual capital, and the organizational advantage", Academy of Management Review, Vol. 23 No. 2, pp. 242-266.

Nguyen, L.T.V., Conduit, J., Lu, V.N. and Hill, S.R. (2020), "Collective empowerment in online communities: conceptualization, scale refinement, and validation", Journal of Marketing Theory and Practice, Vol. 28 No. 3, pp. 301-317. 
Parish, J.T., Cadwallader, S. and Busch, P. (2008), "Want to, need to, ought to: employee commitment to organizational change", Journal of Organizational Change Management, Vol. 21 No. 1, pp. 35-52.

Penley, L.E. and Gould, S. (1988), "Etzioni's model of organizational involvement: a perspective for understanding commitment to organizations", Journal of Organizational Behavior, Vol. 9 No. 1, pp. 43-59.

Poortinga, W. (2006), "Social relations or social capital? Individual and community health effects of bonding social capital", Social Science and Medicine, Vol. 63 No. 1, pp. 255-270.

Ruiz-Palomo, D., León-Gómez, A. and García-Lopera, F. (2020), "Disentangling organizational commitment in hospitality industry: the roles of empowerment, enrichment, satisfaction and gender", International Journal of Hospitality Management, Vol. 90, p. 102637, doi: 10.1016/j.ijhm. 2020.102637.

Subramony, M., Segers, J., Chadwick, C. and Shyamsunder, A. (2018), "Leadership development practice bundles and organizational performance: the mediating role of human capital and social capital", Journal of Business Research, Vol. 83, pp. 120-129.

Teng, H.Y. (2019), "Job crafting and customer service behaviors in the hospitality industry: mediating effect of job passion”, International Journal of Hospitality Management, Vol. 81, pp. 34-42.

Usman, M. and Ahmad, M.I. (2018), "Parallel mediation model of social capital, learning and the adoption of best crop management practices: evidence from Pakistani small farmers", China Agricultural Economic Review, Vol. 10 No. 4, pp. 589-607.

Usman, M., Ali, M., Yousaf, Z., Anwar, F., Waqas, M. and Khan, M.A.S. (2020), "The relationship between laissez-faire leadership and burnout: mediation through work alienation and the moderating role of political skill", Canadian Journal of Administrative Sciences/Revue Canadienne des Sciences de l'Administration, Vol. 37 No. 4, pp. 423-434.

Usman, M., Ali, M., Mughal, F. and Agyemang-Mintah, P. (2021a), "Policy alienation and street-level bureaucrats' psychological wellbeing: the mediating role of alienative commitment”, Journal of Public Administration Research and Theory, Vol. 31 No. 2, pp. 278-294.

Usman, M., Ali, M., Ogbonnaya, C. and Babalola, M.T. (2021b), "Fueling the intrapreneurial spirit: a closer look at how spiritual leadership motivates employee intrapreneurial behaviors", Tourism Management, Vol. 83, 104227, doi: 10.1016/j.tourman.2020.104227.

Veenstra, G. (2000), "Social capital, SES and health: an individual-level analysis", Social Science and Medicine, Vol. 50 No. 5, pp. 619-629.

Wang, M., Guo, T., Ni, Y., Shang, S. and Tang, Z. (2019), "The effect of spiritual leadership on employee effectiveness: an intrinsic motivation perspective", Frontiers in Psychology, Vol. 9 No. 2627, doi: 10.3389/fpsyg.2018.02627.

Yang, F., Liu, J., Wang, Z. and Zhang, Y. (2019), "Feeling energized: a multilevel model of spiritual leadership, leader integrity, relational energy, and job performance", Journal of Business Ethics, Vol. 158 No. 4, pp. 983-997.

\section{Further reading}

Badrinarayanan, V., Madhavaram, S. and Granot, E. (2011), "Global virtual sales teams (GVSTS): a conceptual framework of the influence of intellectual and social capital on effectiveness", Journal of Personal Selling and Sales Management, Vol. 31 No. 3, pp. 311-324.

Chen, M.H., Chang, Y.C. and Hung, S.C. (2008), "Social capital and creativity in R\&D project teams", $R \& D$ Management, Vol. 38 No. 1, pp. 21-34.

Yang, M. and Fry, L.W. (2018), "The role of spiritual leadership in reducing healthcare worker burnout", Journal of Management, Spirituality and Religion, Vol. 15 No. 4, pp. 305-324.

\section{Corresponding author}

Moazzam Ali can be contacted at: moazzamali130@gmail.com

Undermining alienative commitment 


\section{Appendix}

\section{9,4}

1. Spiritual leadership

\section{Vision}

VI1 I Understand and am committed to the vision of leadership in my organization

\section{Altruistic love}

AL1 The leaders in my organization care about their people

AL2 The leaders in my organization are kind and considerate toward workers, and when they are suffering, want to do something about them

AL3 The leaders in my organization "walk the walk" as well as "talk the talk"

AL4 The leaders in my organization do not punish for honest mistakes

AL5 The leaders in my organization are honest and without false pride

AL6 The leaders in my organization are trustworthy and loyal to their employees 0.820

AL7 The leaders in my organization have the courage to stand up for their people $\quad 0.627$

\section{Hope/Faith}

$\mathrm{HF} 1$ I have faith in the leaders in my organization, and I am willing to "do whatever it takes "to make sure that they accomplish the organization' mission

HF2 I persevere and exert extra effort to help my organization's leadership succeed in achieving the organization's goals because I have faith in what they stand for

HF3 I always do my best in my work because I have faith in my organization and its leaders

HF4 I set challenging goals for my work because I have faith in my leaders wants us to succeed

HF5 I demonstrate my faith in the leaders in my organization and their mission by doing everything I can to help us succeed

\section{Social capital}

\section{Structural social capital}

SSC1 I spend significant time on social occasions with people in my organization 0.795

SSC2 I often communicate with people in my organization 0.799

SSC3 I maintain close working relationships with people in my organization $\quad 0.787$

$\begin{array}{lll}\mathrm{SSC} 4 & \text { I Usually exchange ideas and information with people in my organization } & 0.796\end{array}$

SSC5 I frequently interact with people in my organization 0.794

SSC6 I know people in my organization on a personal level 0.754

\section{Relational social capital}

RSC1 Ibelieve I can rely on people in my organization without any fear that they will take advantage of me, even if the opportunity arose

RSC2 People in my organization always keep the promises they make to me

RSC3 The relationships among people in my organization are characterized by mutual friendship

RSC4 The relationships among people in my organization are characterized by high levels of reciprocity

RSC5 I believed that people in my organization approached his or her job with professionalism and dedication

RSC6 Given my track record, I saw no reason to doubt the competence and preparation of people in my organization

\section{Cognitive social capital}

$\begin{array}{ll}\text { CSC1 My organization shares the same ambitions and vision at work } & 0.871\end{array}$

CSC2 People in my organization are enthusiastic about pursuing collective goals 
1. Spiritual leadership

CSC3 People in my organization often agree on what is in the best interest of the relationship

$\mathrm{CSC} 4$ People in my organization share the same business values

0.849

0.735

4. Alienative commitment

$\mathrm{AC1}$ Sometimes I would like to walk out of this organization and never come back

0.697

0.747

0.737

0.663

0.790

AC5 No matter what I do around here, this organization remains unchanged

\section{Political skill}

\section{Networking ability}

NA1 I spend a lot of time and effort at work networking with others

NA2 At work, I know a lot of important people and am well connected

NA3 I am good at using my connections and networks to make things happen at work

0.824

0.787 support when I need to get things done

NA5 I spend a lot of time at work developing connections with others

0.771

0.669

\section{Social astuteness}

SA1 I always seem to instinctively know the right thing to say or due to influence others

0.818

SA2 I have a good intuition or savvy about how to present myself to others

0.703

0.717

0.721

SA4 I pay close attention to people's facial expressions

0.791

\section{Apparent sincerity}

AS1 It is important that people believe I am sincere in what I say and do

AS3 I try to show a genuine interest in other people

0.711

0.818

0.785

0.766

II4 I am good at getting people to like me

0.749

0.725

HF Hope/Faith

CSC Cognitive social capital

3. Political skill as a higher-order construct

Networking ability

AS Apparent sincerity

II Interpersonal influence
Undermining alienative commitment 